\title{
Clinical Study \\ Relation between Red Cell Distribution Width and Left Ventricular Function in Children with Heart Failure
}

\author{
Wegdan Mawlana, Amr Donia, and Doaa Elamrousy \\ Department of the Pediatrics, Tanta University Hospital, Tanta 31125, Egypt \\ Correspondence should be addressed to Wegdan Mawlana; wegdanmawlana@hotmail.com
}

Received 8 November 2013; Accepted 6 January 2014; Published 10 February 2014

Academic Editors: M. Adhikari and G. J. Casimir

Copyright (C) 2014 Wegdan Mawlana et al. This is an open access article distributed under the Creative Commons Attribution License, which permits unrestricted use, distribution, and reproduction in any medium, provided the original work is properly cited.

\begin{abstract}
Background. Most of the studies done on adults showed that red cell distribution width (RDW) can be used as a prognostic marker in patients with chronic heart failure. However, RDW has not been tested in children with heart failure. Methods and Results. 31 children with heart failure admitted to Cardiology Unit, Tanta University Hospital, during the period of January 2012 to December 2012 were included in this study, RDW as a component of routine blood count was evaluated and correlated to the echocardiographic parameters of left ventricle. The mean age of our cohort was $16.16 \pm 14.97$ months, congenital heart disease with left-to-right shunt represented $58.1 \%$ of the underlying causes of heart failure while dilated cardiomyopathy made $41.9 \%$. The mean hemoglobin level was $9.14 \pm 1.18 \mathrm{gm} / \mathrm{dL}$; RDW level ranged from $10.7 \%$ to $27.7 \%$ with a mean of $16.01 \pm 3.34$. Hemoglobin was significantly correlated with RDW at any level. For the echo parameters, at cutoff point of $16.4 \%, \mathrm{RDW}$ was significantly correlated with fraction shortening (FS), and $A, E / A$ ratio, but it was not correlated with LVEDD, LVESD, and $E / E$ at the same cutoff level. Conclusion. RDW, a simple, available test, can be used as a marker for the left ventricular function in children with heart failure until an echocardiography assessment for the patients is done.
\end{abstract}

\section{Background}

Red cell distribution width (RDW) measures the variation in the size of erythrocytes. It has been used to differentiate iron deficiency anemia from thalassemia trait, where increased RDW is associated with iron deficiency anemia $[1,2]$. The association between anemia and cardiovascular outcome has been studied in the adult population. RDW has been recently discovered as a new marker in heart failure. It was found that increased RDW was associated with increased morbidity and mortality in chronic heart failure [3]. There is no definite pathophysiology explaining this association. Several factors may be proposed including inflammation, nutritional deficiencies, and inadequate production of erythropoietin [4-6]. Congestive heart failure is the most common cause for admission to the Pediatric Cardiology Unit at Tanta University Hospital. Congenital heart diseases with left-to-right shunt as VSD and PDA represent the majority of cases with heart failure; acute exacerbation of chronic heart failure in children with dilated cardiomyopathy forms another group. Several cardiac biomarkers have been tested as predictors for the severity of heart failure including brain natriuretic peptide, N-terminal pro-BNP (NT-proBNP), and cardiac troponins $[7,8]$. RDW is a component of routine complete blood count done for all patients admitted with the diagnosis of heart failure. However, the relation between RDW and left ventricular function assessed by echocardiography has not been studied in children.

\section{Patients and Methods}

This is a prospective randomized study done on 31 children who were admitted to the Pediatric Cardiology Unit at Tanta University Hospital during the period from January 2012 to December 2012 with clinical diagnosis of heart failure. Study approval was obtained by the local ethics committee. For all patients, Complete blood count with RDW was measured with the use of an analyzer on the day of admission.

Two-dimensional echocardiography was performed and analyzed in all the patients on admission using Ultrasound Machine, Vivid 7 (GE) medical system, Horten, Norway with 
3.5 multi-frequency transducer. Fractional shortening was measured using the equation $(\mathrm{FS}=\mathrm{Dd}-\mathrm{Ds} / \mathrm{Dd} \times 100)$ where $\mathrm{Dd}$ is the end-diastolic dimension of the left ventricle (LV) and Ds is the end-systolic dimension of the LV.

Pulsed-wave Doppler echocardiography of the mitral inflow was performed for all the children to measure peak velocity of early diastolic filling $(E)$, late filling $(A)$. All the children underwent tissue Doppler imaging (TDI) to measure early diastolic mitral annular velocity $(E)$ and $(E / E)$ ratio was calculated.

\section{Statistical Analysis}

The relation between different values of RDW and various echocardiographic parameters were tabulated and statistically analyzed to explore any significant results. Numerical variables were presented using mean and standard deviations; categorical variables were described using numbers and percentages. Comparisons of continuous variables were done using the unpaired Students $t$-test. Correlations of RDW with various echo parameters were examined by Pearson correlation analysis. For RDW we used 16.4\% (median) as a cutoff point to examine if RDW above $16.4 \%$ was useful to predict impaired left ventricular function. $P<0.05$ was considered statistically significant.

\section{Results}

Tables 1 and 2 demonstrate the baseline characteristics of our cohort with heart failure. Our study group consisted of 31 children with male sex representing $38.7 \%$ (12 males). Their age ranged from 2 months to 60 months with mean of $16.16 \pm$ 14.97 months. $41.9 \%$ of our patients were diagnosed as dilated cardiomyopathy while congenital heart disease (CHD) with left-to-right shunt representing 58.1\%. Isolated VSD formed the main CHD among the studied group (26.81\%). Hg ranged from $7.2 \mathrm{gm} / \mathrm{dL}$ to $12.2 \mathrm{gm} / \mathrm{dL}$ with mean of $9.14 \pm 1.18 \mathrm{gm} / \mathrm{dL}$. The mean value of RDW was $16.01 \pm 3.34$ with the range of 10.70 to $27.7 \%$. There were no significant differences between male and female children with respect to the age and different laboratory and echocardiographic parameters (Table 3).

This study investigated the relation between RDW and different laboratory and echo parameters as presented in Table 4. The optimal cutoff value of RDW was $16.4 \%$ (median); RDW level was significantly related to hemoglobin level $(P=0.047)$, fraction shortening $(\mathrm{FS})(P=0.003)$, $A(P=0.12)$, and $E / A$ ratio $(P=0.012)$. However, age $(P=0.058), \operatorname{LVEDD}(P=0.170), \operatorname{LVESD}(P=0.156)$, and $E(P=0.123)$ were not significantly related to RDW level.

We studied if RDW level $\geq 16.4$ was associated with higher $E / E$ in our group; however there was no significant correlation between $E / E$ and RDW at a level of $\geq 16.4 \%$. Table 5 summarizes the echo parameters that significantly correlated with RDW.
TABLE 1: Demographic characteristics and etiology of heart failure in study group.

\begin{tabular}{lcc}
\hline & $N$ & $\%$ \\
\hline Sex & 12 & \\
Male & 19 & 38.71 \\
$\quad$ Female & & 61.29 \\
Cause of Heart Failure & 5 & 16.13 \\
VSD/ASD & 13 & 41.94 \\
DCM & 1 & 3.23 \\
ASD & 8 & 26.81 \\
VSD & 2 & 6.45 \\
PDA/VSD & 1 & 3.23 \\
PDA & 1 & 3.23 \\
CAVC & & \\
\hline
\end{tabular}

VSD: ventricular septal defect; ASD: atrial septal defect; DCM: dilated cardiomyopathy; DA: patent ductus arteriosus; CAVC: common atrioventricular canal.

TABLE 2: Laboratory and echocardiographic parameters of children with heart failure.

\begin{tabular}{lcc}
\hline & Range & Mean \pm SD \\
\hline Age (Month) & $2.000-60.000$ & $16.161 \pm 14.971$ \\
Hb $(\mathrm{gm})$ & $7.200-12.200$ & $9.142 \pm 1.180$ \\
RDW $(\%)$ & $10.700-27.700$ & $16.019 \pm 3.348$ \\
FS $(\%)$ & $7.220-51.700$ & $24.974 \pm 14.512$ \\
LVEDD $(\mathrm{cm})$ & $1.600-5.100$ & $3.206 \pm 1.403$ \\
LVESD $(\mathrm{cm})$ & $0.900-4.600$ & $2.516 \pm 1.523$ \\
$E(\mathrm{~m} / \mathrm{s})$ & $0.390-1.000$ & $0.699 \pm 0.181$ \\
$A(\mathrm{~m} / \mathrm{s})$ & $0.280-1.290$ & $0.624 \pm 0.342$ \\
E/A & $0.600-2.000$ & $1.328 \pm 0.514$ \\
$E / E$ & $0.750-17.500$ & $12.339 \pm 4.538$ \\
\hline
\end{tabular}

Hb: hemoglobin; RDW: red cell distribution width; FS: fraction shortening; LVEDD: left ventricular end diastolic dimension; LVESD: left ventricular end systolic dimension; $E$ : peak velocity of early diastolic filling; $A$ : peak velocity of late filling; $E / E$ : early mitral inflow velocity to early diastolic mitral annular velocity ratio.

\section{Discussion}

A wide variety of biological markers have been used as a predictive for morbidity and mortality in patients with heart failure; however, many of them are still used for research only [9].

Evaluation of routine laboratory values as marker for heart failure has not been given much interest. red cell distribution width (RDW), a variation in the size of erythrocytes, has been investigated as a new marker in cardiac disease [10]. It is readily available with routine CBC. RDW is elevated either due to impaired production or increased destruction of erythrocytes.

The interaction between heart failure and hematological system is not well understood. Among the several potential causes of this association, inflammatory cytokines as TNF- $\alpha$ as well as IL- 6 have been shown to be predictors in heart failure; these cytokines may impact bone marrow function and iron metabolism. This supports the basic role of inflammation 
TABLE 3: The difference between both sexes in laboratory and echoparameters.

\begin{tabular}{lcccc}
\hline & Male & Female & \multicolumn{2}{c}{$t$-test } \\
& Mean \pm SD & Mean \pm SD & $t$ & $P$-value \\
\hline Age $(\mathrm{month})$ & $8.667 \pm 7.152$ & $20.895 \pm 16.769$ & -2.381 & 0.024 \\
$\mathrm{Hb}(\mathrm{gm} / \mathrm{dL})$ & $9.533 \pm 1.476$ & $8.895 \pm 0.906$ & 1.498 & 0.145 \\
$\mathrm{RDW}(\%)$ & $15.758 \pm 4.772$ & $16.184 \pm 2.166$ & -0.340 & 0.736 \\
$\mathrm{FS}(\%)$ & $30.889 \pm 12.880$ & $21.238 \pm 14.544$ & 1.878 & 0.070 \\
LVEDD $(\mathrm{cm} / \mathrm{s})$ & $2.350 \pm 0.799$ & $3.747 \pm 1.446$ & -3.054 & 0.005 \\
LVESD $(\mathrm{cm} / \mathrm{s})$ & $1.675 \pm 0.730$ & $3.047 \pm 1.665$ & -2.684 & 0.012 \\
$E(\mathrm{~cm} / \mathrm{s})$ & $0.691 \pm 0.229$ & $0.704 \pm 0.151$ & -0.189 & 0.851 \\
$A(\mathrm{~cm} / \mathrm{s})$ & $0.728 \pm 0.362$ & $0.558 \pm 0.320$ & 1.361 & 0.184 \\
$E / A$ & $1.080 \pm 0.491$ & $1.485 \pm 0.476$ & -2.283 & 0.030 \\
$E / E$ & $12.117 \pm 4.045$ & $12.479 \pm 4.926$ & -0.213 & 0.833 \\
\hline
\end{tabular}

Hb: hemoglobin; RDW: red cell distribution width; FS: fraction shortening; LVEDD: left ventricular end diastolic dimension; LVESD: left ventricular end systolic dimension; $E$ : peak velocity of early diastolic filling; $A$ : peak velocity of late filling; $E / E$ : early mitral inflow velocity to early diastolic mitral annular velocity ratio.

TABLE 4: Laboratory and echocardiographic parameters stratified by RDW value.

\begin{tabular}{lcccc}
\hline & $<16.4$ & $>16.4$ & \multicolumn{2}{c}{$t$-test } \\
& Mean \pm SD & Mean \pm SD & $t$ & $P$ value \\
\hline Age $(\mathrm{month})$ & $21.400 \pm 18.616$ & $11.250 \pm 8.466$ & 1.976 & 0.058 \\
$\mathrm{Hb}(\mathrm{gm} / \mathrm{dL})$ & $9.573 \pm 1.015$ & $8.738 \pm 1.209$ & 2.077 & $0.047^{*}$ \\
$\mathrm{FS}(\%)$ & $17.426 \pm 9.957$ & $32.050 \pm 14.773$ & -3.209 & $0.003^{*}$ \\
$\mathrm{LVEDD}(\mathrm{cm} / \mathrm{s})$ & $3.567 \pm 1.262$ & $2.869 \pm 1.482$ & 1.407 & 0.170 \\
$\mathrm{LVESD}(\mathrm{cm} / \mathrm{s})$ & $2.920 \pm 1.428$ & $2.138 \pm 1.556$ & 1.456 & 0.156 \\
$E(\mathrm{~cm} / \mathrm{s})$ & $0.647 \pm 0.148$ & $0.748 \pm 0.200$ & -1.586 & 0.123 \\
$A(\mathrm{~cm} / \mathrm{s})$ & $0.448 \pm 0.125$ & $0.789 \pm 0.398$ & -3.166 & $0.004^{*}$ \\
$E / A$ & $1.562 \pm 0.527$ & $1.109 \pm 0.404$ & 2.693 & $0.012^{*}$ \\
$E / E$ & $13.800 \pm 3.680$ & $10.969 \pm 4.940$ & 1.800 & 0.082 \\
\hline
\end{tabular}

${ }^{*}$ Significant.

Hb: hemoglobin; RDW: red cell distribution width; FS: fraction shortening; LVEDD: left ventricular end diastolic dimension; LVESD: left ventricular end systolic dimension; $E$ : peak velocity of early diastolic filling; $A$ : peak velocity of late filling; $E / E$ : early mitral inflow velocity to early diastolic mitral annular velocity ratio.

TABLE 5: Factors affecting RDW value.

\begin{tabular}{lcccc}
\hline & $<16.4$ & $>16.4$ & \multicolumn{2}{c}{$t$-test } \\
& Mean \pm SD & Mean \pm SD & $t$ & $P$ value \\
\hline $\mathrm{Hb}(\mathrm{gm} / \mathrm{dL})$ & $9.573 \pm 1.015$ & $8.738 \pm 1.209$ & 2.077 & $0.047^{*}$ \\
$\mathrm{FS}(\%)$ & $17.426 \pm 9.957$ & $32.050 \pm 14.773$ & -3.209 & $0.003^{*}$ \\
$A$ & $0.448 \pm 0.125$ & $0.789 \pm 0.398$ & -3.166 & $0.004^{*}$ \\
$E / A$ & $1.562 \pm 0.527$ & $1.109 \pm 0.404$ & 2.693 & $0.012^{*}$ \\
\hline
\end{tabular}

${ }^{*}$ Significant.

in the induction of ineffective red cell production, reflected by increased RDW values [11].

Most of the studies investigated RDW as prognostic marker in adults with chronic heart failure $[12,13]$. To our knowledge, none of these studies focused on heart failure within the pediatric age group. Our cohort included children admitted with heart failure. congenital heart diseases with left-to-right shunt representing 58.1\%, with VSD represent $26.7 \%$, then comes dilated cardiomyopathy as the second cause of heart failure in the studied group (41.9\%).

Our study showed that RDW correlated significantly with hemoglobin, this in in agreement with the study done by Felker et al. 2007, which showed that RDW and hemoglobin were negatively correlated with each other. Previous studies examining the relationship between hemoglobin and severity of cardiac failure showed that low hemoglobin was associated with adverse outcome. Most recently Increased RDW was shown to be a strong predictor of increased morbidity and mortality in patients with chronic heart failure [3]. In view of these studies, we can use RDW as a prognostic factor for our patients but we should be cautious when interpreting these results as most of these studies were conducted in adults with chronic heart failure.

Other principal findings in this study are that the RDW level at cutoff point of $16.4 \%$ was significantly correlated with the echo parameters such as FS, and $A$ velocity, $E / A$ ratio, and was not correlated with the $E$ velocity and $E / E$ ratio. These results are in concordance at some points with the study done by $\mathrm{OH}$ et al., 2009 [14], which reported significant correlation between RDW and echo parameters such as E velocity, and $E / E$ ratio. Our study did not show correlation with $E / E$ ratio which could be explained by the small number of our cohort.

The current study has some limitations that should be considered when evaluating our results. Small number of the studied group may impact the results; large numbers of patients would strengthen the results, further study needed to correlate serial RDW with the clinical severity of heart failure as well as follow-up of the patient as regards frequent hospitalization and or death.

In conclusion, RDW, which is routinely measured and reported as a component of the standard complete blood count, was significantly correlated with hemoglobin and echo parameters for evaluation of left ventricular function in children with heart failure. This emphasizes that elevated $\mathrm{RDW}$ can be used as a novel marker in children with heart failure. This study should prompt further evaluation of the association between RWD and outcome in children with heart failure to improve understanding of the pathophysiology of heart failure. We suggested the RDW as a simple test can be used as a marker for heart failure in emergency room.

\section{Conflict of Interests}

The authors declare that there is no conflict of interests regarding the publication of this paper.

\section{References}

[1] M. Morris and F. R. Davey, "Basic examination of blood," in Henry's Clinical Diagnosis and Management by Laboratory Methods, J. B. Henry, Ed., W.B. Saunders, Philadelphia, Pa, USA, 20th edition, 2001.

[2] A. Demir, N. Yarali, T. Fisgin, F. Duru, and A. Kara, "Most reliable indices in differentiation between thalassemia trait and 
iron deficiency anemia," Pediatrics International, vol. 44, no. 6, pp. 612-616, 2002.

[3] G. M. Felker, L. A. Allen, S. J. Pocock et al., "Red cell distribution width as a novel prognostic marker in heart failure: data from the CHARM program and the Duke Databank," Journal of the American College of Cardiology, vol. 50, no. 1, pp. 40-47, 2007.

[4] M. Tonelli, F. Sacks, M. Arnold, L. Moye, B. Davis, and M. Pfeffer, "Relation between red blood cell distribution width and cardiovascular event rate in people with coronary disease," Circulation, vol. 117, no. 2, pp. 163-168, 2008.

[5] K. Kario, T. Matsuo, K. Nakao, and N. Yamaguchi, "The correlation between red cell distribution width and serum erythropoietin titres," Clinical \& Laboratory Haematology, vol. 13, no. 2, pp. 222-223, 1991.

[6] G. Lippi, G. Targher, M. Montagnana, G. L. Salvagno, G. Zoppini, and G. C. Guidi, "Relation between red blood cell distribution width and inflammatory biomarkers in a large cohort of unselected outpatients," Archives of Pathology \& Laboratory Medicine, vol. 133, no. 4, pp. 628-632, 2009.

[7] P. Kubler, E. A. Jankowska, J. Majda, K. Reczuch, W. Banasiak, and P. Ponikowski, "Lack of decrease in plasma N-terminal probrain natriuretic peptide identifies acute heart failure patients with very poor outcome," International Journal of Cardiology, vol. 129, no. 3, pp. 373-378, 2008.

[8] M. Metra, S. Nodari, G. Parrinello et al., "The role of plasma biomarkers in acute heart failure. Serial changes and independent prognostic value of NT-proBNP and cardiac troponin-T," European Journal of Heart Failure, vol. 9, no. 8, pp. 776-786, 2007.

[9] S. J. Pocock, D. Wang, M. A. Pfeffer et al., "Predictors of mortality and morbidity in patients with chronic heart failure," European Heart Journal, vol. 27, no. 1, pp. 65-75, 2006.

[10] Z. Förhécz, T. Gombos, G. Borgulya, Z. Pozsonyi, Z. Prohászka, and L. Jánoskuti, "Red cell distribution width in heart failure: prediction of clinical events and relationship with markers of ineffective erythropoiesis, inflammation, renal function, and nutritional state," American Heart Journal, vol. 158, no. 4, pp. 659-666, 2009.

[11] C. A. Cauthen, W. Tong, A. Jain, and W. H. W. Tang, "Progressive rise in red cell distribution width is associated with disease progression in ambulatory patients with chronic heart failure," Journal of Cardiac Failure, vol. 18, no. 2, pp. 146-152, 2012.

[12] L. A. Allen, G. M. Felker, M. R. Mehra et al., "Validation and potential mechanisms of red cell distribution width as a prognostic marker in heart failure," Journal of Cardiac Failure, vol. 16, no. 3, pp. 230-238, 2010.

[13] W. H. Tang, W. Tong, A. Jain, G. S. Francis, C. M. Harris, and J. B. Young, "Evaluation and long-term prognosis of newonset, transient, and persistent anemia in ambulatory patients with chronic heart failure," Journal of the American College of Cardiology, vol. 51, no. 5, pp. 569-576, 2008.

[14] J. Oh, S.-M. Kang, N. Hong et al., "Relation between red cell distribution width with echocardiographic parameters in patients with acute heart failure," Journal of Cardiac Failure, vol. 15, no. 6, pp. 517-522, 2009. 


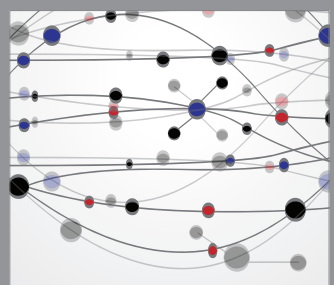

The Scientific World Journal
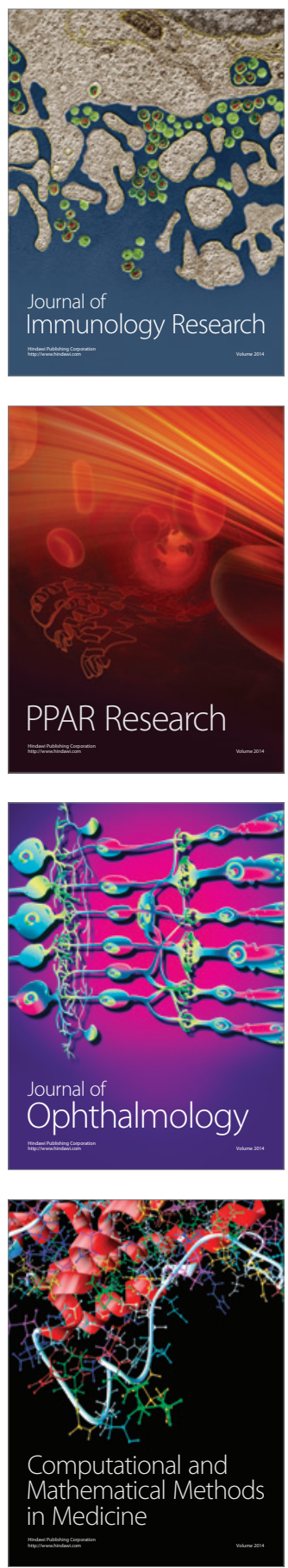

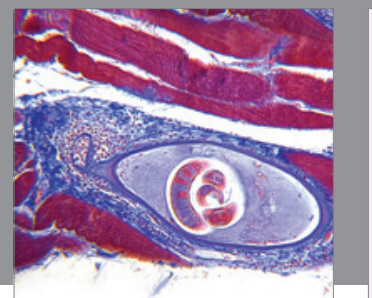

Gastroenterology

Research and Practice
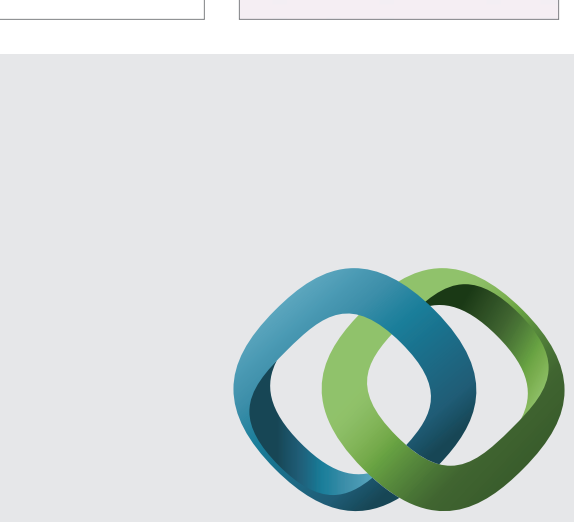

\section{Hindawi}

Submit your manuscripts at

http://www.hindawi.com
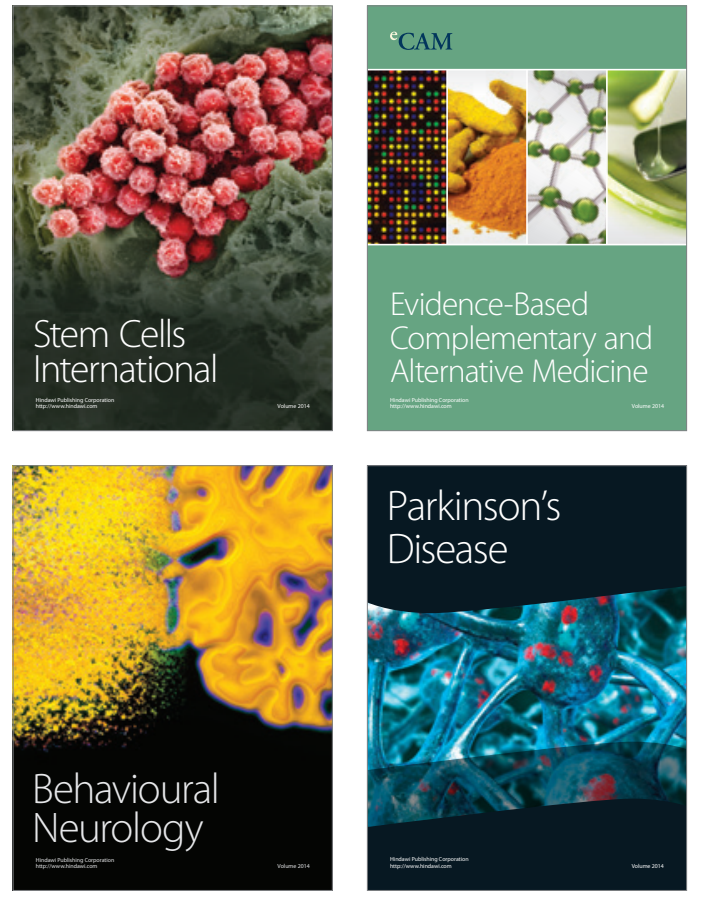
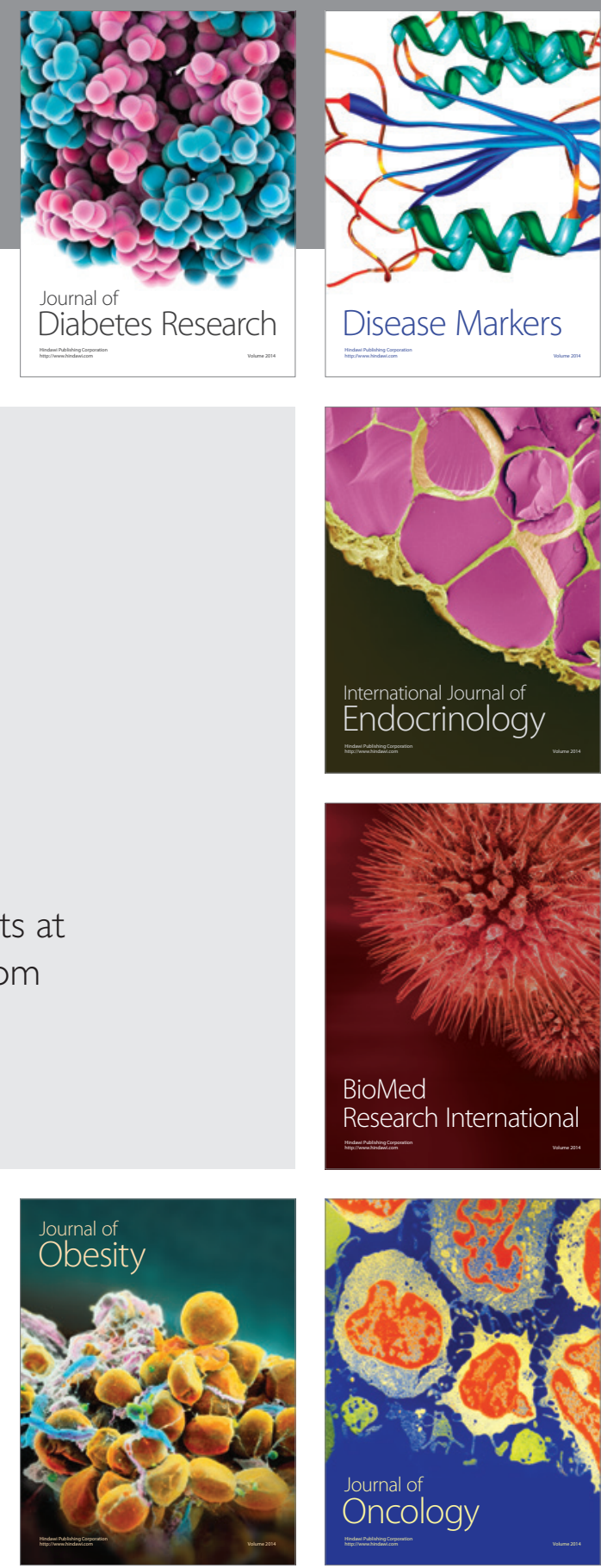

Disease Markers
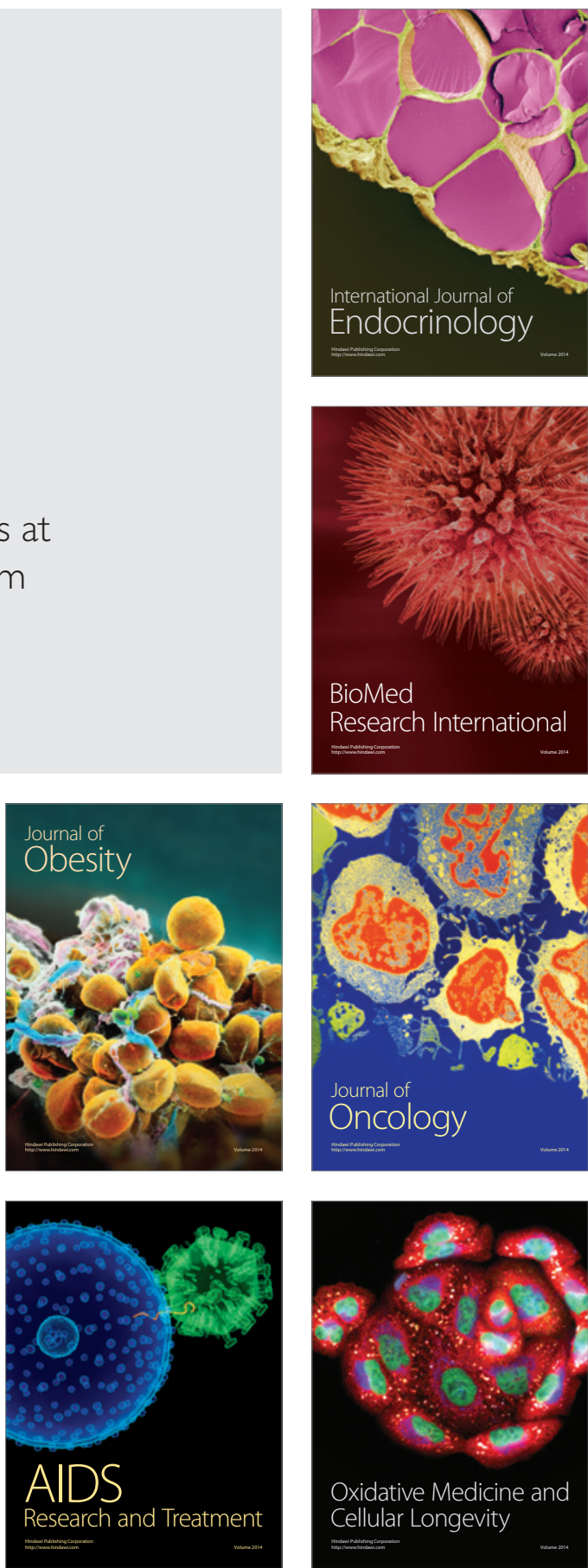